\title{
Avaliação de Instituições de Ensino Superior: discutindo a necessidade de diretrizes metodológicas e estratégias de implantação
}

\author{
CLARILZA PRADO DE SOUSA \\ Professora da Pontifícia Universidade Católica de São Paulo e \\ pesquisadora da Fundação Carlos Chagas \\ cprado@fcc.org.br
}

\begin{abstract}
Resumo
A auto-avaliação institucional de uma universidade, tal como foi proposta pela Lei n. 10861 , de 14 de abril de 2004, que cria o Sistema Nacional de Avaliação da Educação Superior Sinaes -, é, sem dúvida, uma atividade extremamente significativa e permite à instituição não somente ter um diagnóstico de sua trajetória como também reafirmar sua identidade social. As diretrizes estabelecidas no documento Bases para uma nova proposta de avaliação da educação superior, elaborado pelo Ministério da Educação, procura abranger diferentes e complexas dimensões de análise. Este texto procura discutir diretrizes metodológicas que poderiam ser consideradas em um plano de implantação da auto-avaliação, a ser proposto pelo Coordenação Nacional de Avaliação do Ensino Superior do Ministério da Educação.

Palavras-chaves: auto-avaliação institucional, implantação de auto-avaliação, metodologia de auto-avaliação.
\end{abstract}

\section{Resumen}

La auto evaluación institucional de una universidad tal como fue propuesta por la Ley $\mathrm{n}^{\circ}$ 10861, de 14 de Abril de 2004 que crea el Sistema Nacional de Evaluación de la Educación Superior - SINAES - es, sin duda, una actividad de gran significado y permite a la institución no solo tener un diagnóstico de su trayectoria, como también reafirmar su identidad social. Las directrices establecidas en el documento Bases para una nueva propuesta de evaluación de la educación superior elaborado por el Ministerio de Educación procura abarcar diferentes y complejas dimensiones de análisis. El presente texto busca discutir directrices metodológicas que podrían ser consideradas en un plano de implementación de la auto evaluación, a ser propuesto por la Coordinación Nacional de Evaluación de la Enseñanza Superior del Ministerio de Educación.

Palabras-clave: auto evaluación institucional, implementación de auto evaluación, metodología de auto evaluación.

\begin{abstract}
Institutional self-assessment at university level, as put down by Law nr. 10 861, of April 14, 2004, which created the National System of Higher Education Assessment - SINAES - is, without a doubt, an important activity and allows the institution not only to obtain a diagnosis of its course of action as well as to reaffirm its social identity. The rules established
\end{abstract}


in the document Guidelines for a new proposal for higher education assessment, designed by the Ministry of Education, aims at comprehensive and complex dimensions of analysis. This article will discuss methodological guidelines that could be taken into account in a plan to introduce self-assessment, as is to be proposed by the Ministry of Education's National Coordination of Higher Education Assessment.

Key words: institutional self-assessment, introduction of self-assessment, self-assessment methodology. 
A auto-avaliação institucional de uma universidade, tal como foi proposta pela Lei n. 10.861, de 14 de abril de 2004, que cria o Sistema Nacional de Avaliação da Educação Superior - Sinaes -, coordenada pelo Ministério da Educação/Instituto Nacional de Estudos e Pesquisas/Cooordenação Nacional de Avaliação do Ensino Superior MEC/Inep/Conaes -, é, sem dúvida, uma atividade muito mais complexa do que imaginava quando iniciei as atividades de coordenação do processo auto-avaliativo de uma instituição de ensino superior - IES.

Tendo trabalhado em processos de avaliação durante toda a vida profissional, tinha a impressão de que enfrentaria mais um desafio, mas com plenas condições de ultrapassá-lo. Convencida que estava, e ainda estou, dos propósitos declarados pelos documentos e seminários promovidos pelo MEC/Inep/Conaes, lancei-me, com outras colegas ${ }^{1}$, na promoção da auto-avaliação institucional, sem me dar conta de que a complexidade da proposta poderia dificultar a possibilidade de construir, com a avaliação, um processo de tomada de decisão. Considerando que um processo avaliativo somente se realiza quando subsidia o processo de tomada de decisões, indicar que a complexidade da proposta de autoavaliação pode comprometer o processo de tomada de decisão é afirmar que há problemas a serem ponderados, como pretendo analisar, no processo de implantação da referida proposta.

Tal proposta, procurando abranger as diferentes dimensões que envolvem a análise de uma instituição de ensino superior, abre um leque tão grande de dados a serem coletados e analisados que, se não for adotada uma estratégia que torne possível o seu desenvolvimento, mantendo as diretrizes do processo, poderá comprometer o caráter formativo e formador pretendido com a avaliação e, assim, frustrar a construção de uma cultura de avaliação na instituição.

O documento do MEC/Inep/Conaes - Bases para uma nova proposta de avaliação da educação superior (que será referido aqui como Documento Bases) - define dez importantes dimensões avaliativas apresentadas no Quadro 1: missão institucional; políticas de ensino, pesquisa, extensão da graduação e pós-graduação; responsabilidade social da instituição; comunicação com a sociedade; políticas de pessoal, de carreiras do corpo docente, administrativo e técnico; organização e gestão da instituição; infraestrutura física; planejamento de avaliação; políticas de atendimento ao estudante e egressos; sustentabilidade financeira.

\footnotetext{
1 Refiro-me às especialistas em avaliação educacional Dra. Anamérica Prado Marcondes, Dra. Sandra Ferreira Acosta e aos demais participantes, também membros da CPA da PUCSP.
} 
Quadro 1 - Dimensões do Documento Bases

Dimensões de análise propostos pelo Conaes/Inep

1. A missão e o plano de desenvolvimento institucional;

2. a política para o ensino, pesquisa, extensão, pós-graduação e as respectivas normas de operacionalização, incluídos os procedimentos para estímulo à produção acadêmica, às bolsas de pesquisa, de monitoria e demais modalidades;

3. a responsabilidade social da instituição, considerada especialmente no que se refere à sua contribuição sobre inclusão social, desenvolvimento econômico e social, defesa do meio ambiente, memória cultural, produção artística e patrimônio cultural;

4. a comunicação com a sociedade;

5. as politicas de pessoal, de carreiras do corpo docente e corpo técnicoadministrativo, seu aperfeiçoamento, desenvolvimento profissional e suas condições de trabalho;

6. a organização e gestão da instituição, especialmente o funcionamento e representatividade dos colegiados, sua independência e economia na relação com a mantenedora, e a participação dos segmentos da comunidade universitária nos processos decisórios;

7. a infra-estrutura física, especialmente a de ensino e de pesquisa, biblioteca, recursos de informação e comunicação;

8. o planejamento de avaliação, especialmente em relação aos processos, resultados e eficácia da auto-avaliação institucional;

9. as politicas de atendimento a estudantes e egressos; $\mathrm{e}$

10. a sustentabilidade financeira, tendo em vista o significado social da continuidade dos compromissos na oferta da educação superior.

Para análise dessas dimensões são descritas questões orientadoras e um grande número de indicadores que têm como função permitir a adequada análise às propostas. Tais indicadores, por sua vez, para serem corretamente analisados, exigem um considerável levantamento e cruzamento de dados da instituição.

Tendo em vista a importância da proposta, discuto aqui a necessidade de diretrizes metodológicas e de estratégias de implantação pelo MEC/Inep/Conaes, para que não se corra o risco de permitir a realização de relatórios pro forma, apenas de prestação de contas, sem produzir uma reflexão que conduziria à tomada de decisão, conforme 
determina o Documento Bases, que afirma a necessidade de que os dados construam consciências pedagógicas sobre as diferentes funções da instituição.

As funções mais importantes da auto-avaliação permanente são a de produzir conhecimentos, pôr em questão a realização das finalidades essenciais, identificar as causalidades dos problemas e deficiências, aumentar a consciência pedagógica e a capacidade profissional dos professores, tornar mais efetiva a vinculação da instituição com o entorno social e a comunidade mais ampla, julgar acerca da relevância científica e social de suas atividades e seus produtos, prestar constas à sociedade, justificar publicamente sua existência e fornecer todas as informações que sejam necessárias ao conhecimento do Estado e da população. (p.96)

A importância de uma avaliação com tais propósitos é crucial, hoje, para as universidades brasileiras, e soa como um contraponto no cenário de gestões autoritárias, e sem compromissos sociais, claros e transparentes, em que muitas IES estão mergulhadas. Assim, visando a oferecer uma contribuição, apresento alguns dos princípios metodológicos que fui consolidando em minha experiência na coordenação de avaliações institucionais, a fim de que, uma vez compartilhados com outros colegas que assumiram, como eu, a tarefa de desenvolver tais avaliações em instituições, possamos aprofundar e discutir essas considerações, contribuindo assim com subsídios para as orientações do MEC/Inep/Conaes.

\section{A AVALIAÇÃO DEVE SER SIMPLES}

A qualidade de um processo de auto-avaliação não está restrita à sofisticação, à dificuldade e à complexidade de seus procedimentos. Um bom processo avaliativo é aquele que é compreendido, com facilidade, por todos os atores da comunidade universitária (professores, alunos e funcionários). Principalmente, é um processo que necessita ser assumido de modo adequado e que corresponda às necessidades de análise da instituição. O processo avaliativo não deve ser subordinado aos interesses de uma gestão universitária, mas a própria gestão poderá entendê-lo como uma forma legítima de retratar as dificuldades, as facilidades e a busca de caminhos.

Nestes termos, o princípio básico que orienta a auto-avaliação é o que lhe confere legitimidade, e isso pode exigir simplificações, ou 
facilitações, em prol de melhores condições de análise e interpretação dos dados, para todos os participantes da instituição.

Ao propor uma simplificação do processo de auto-avaliação, não sugiro uma modificação das dimensões avaliativas, da função de universidade que sustenta o Documento Bases, mas indico a necessidade de o MEC/Inep/Conaes propor uma estratégia que favoreça a utilização de procedimentos a serem implementados gradativamente e que levem a um aprofundamento constante. Essa estratégia deve prever a implantação de todos os elementos propostos no Documento Bases como uma meta, para a instituição, em tempo previsto.

Quantos anos? Quanto tempo?

Dependeria da instituição, do planejamento que a própria autoavaliação realizasse, do acordo que seria estabelecido entre a instituição e o MEC/Inep/Conaes. Pretender analisar, em um período de dois anos, o ensino, a extensão, a pesquisa, os alunos egressos, a função social da instituição, a responsabilidade assumida diante da sociedade, os seus processos de gestão, a sua organização administrativa e acadêmica, as suas possibilidades econômicas e financeiras é, sem dúvida, aceitar a possibilidade de análises mais superficiais e perder a oportunidade de fazer a comunidade universitária tomar conhecimento dos resultados e enfrentar de maneira consciente as decisões fundamentais para a universidade.

Thélot (1003), ao discutir processos avaliativos, afirma:

é preciso ser simples, mais precisamente encontrar um bom equilíbrio entre simplicidade e complexidade na busca de indicadores. Em particular, e isto deve ser uma regra imperativa, importa limitar a um número pequeno de indicadores. Nada é mais inútil, ou melhor dizendo, nada é mais dissuasivo que avaliar um área ou uma ação com a ajuda de centenas de indicadores. (p.28)

Desse modo, o que se sugere é que o Documento Bases estabeleça um equilíbrio entre simplicidade e complexidade, possibilitando implantar uma auto-avaliação que construa prioridades no processo de reflexão da universidade. A priorização, quando realizada pela própria IES, já permitiria analisar como a universidade analisa e estrutura o pensamento a respeito de si mesma. Comparar essa priorização com a missão declarada da instituição seria um dos tópicos possíveis de avaliação, o que permitiria à avaliação externa acrescentar novos elementos em sua análise. 


\section{A AVALIAÇÃO DEVE CONTRIBUIR PARA REFORÇAR A IDENTIDADE DA INSTITUIÇÃO: IDENTIFICANDO OS ASPETOS COMUNS E OS ESPECÍFICOS}

\section{O que nos une e o que nos separa?}

A identidade de uma instituição de ensino superior, à semelhança de outras instituições sociais, pode ser vista como um construto e não como "algo que se encontra por aí in natura", conforme declara Rajagopalan (2002). Nesse sentido, não pode ser vista como estável, unificada e claramente delineada, como também não pode ser compreendida somente como um conjunto de interações sociais. A identidade de uma IES é construída por um conjunto de significações e de políticas de representações (Rajagopalan, 2002) que se afirmam no cotidiano; isso indica que, para entendê-la, é preciso considerar a trajetória das mudanças e mutações que assinalam a sua existência.

O Documento Bases relaciona indicadores nucleares que possibilitarão a análise da instituição em um tempo estabelecido, a comparação de sua evolução em períodos determinados e ainda a avaliação entre instituições semelhantes. É na comparação com outras instituições e com a sua própria história que cada instituição afirma a própria identidade e traça as metas para o futuro, definindo sua função social. A compreensão dos indicadores, nessa perspectiva, precisa ter como pano de fundo o desvelar da identidade institucional, os valores a serem afirmados, a visão geral que permite defini-la como instituição de ensino superior e, ao mesmo tempo, distingui-la mediante sua especificidade.

As características fundamentais da nova proposta são: a avaliação institucional como centro do processo avaliativo; a integração de diversos instrumentos com base em uma concepção global e no respeito à identidade e à diversidade institucionais. Tais características possibilitam levar em conta a realidade e a missão de cada IES, ressalvando o que há de comum e universal na Educação Superior e as especificidades das áreas do conhecimento. (Brasil, 2004, p. 7)

Nesses termos, a reflexão sobre a escolha de indicadores é um processo auto-avaliativo, uma vez que permite à instituição a análise e a escolha da própria imagem e dos filtros a serem usados no processo. Essa é uma etapa da metodologia avaliativa que ultrapassa o momento de sensibilização previsto no Documento Bases e que permite se construa perante a comunidade o sentido da implantação de um processo avaliativo, contínuo e rotineiro na instituição. 
Assim, não se propõe desconsiderar os indicadores, os quais entendo como fundamentais, mas se assinala que, para serem assumidos, precisariam ser resignificados e, até, ampliados, no contexto da instituição. Somente a apropriação coletiva desses indicadores evitaria que a tarefa de avaliação se tornasse uma atividade de avaliadores responsáveis apenas perante o MEC/Inep/Conaes em atendimento a dados "solicitados".

Para garantir que essas diretrizes se tornem procedimentos metodológicos, e resultem em processos de conscientização acadêmica, seria conveniente que o Documento Bases enfatizasse estratégias de implantação da auto-avaliação, e criasse possibilidades para as instituições comprometerem-se com o aprofundamento de suas reflexões. Melhor dizendo, processos orientadores de avaliação, propostos pelos órgãos reguladores do sistema de ensino, precisariam indicar não somente o que fazer, o propósitos de um processo avaliativo, mas apresentar sugestões de como fazer, de como favorecer a compreensão dos limites para implantá-lo, e indicar mais claramente o alcance pretendido com as orientações.

\section{AVALIAÇÃO NÃO É REGULAÇÃO, MAS ESTA É NECESSÁRIA À UNIVERSIDADE}

Implantar a auto-avaliação, supervisionada pelo Ministério da Educação, envolve, necessariamente, discutir a relação entre a avaliação e a regulação do ensino superior. Garantir a autonomia das universidades, hoje, contraditoriamente, exige, de órgãos como o MEC e, principalmente, o Conselho Nacional de Educação e os Conselhos Estaduais de Educação, que não abdiquem de sua função reguladora. $\mathrm{O}$ desenvolvimento no país de estabelecimentos de ensino superior que "mercantilizam" o ensino, movidos por lucros imediatos, não evidenciando políticas internas para a qualidade do ensino e para a construção de um clima acadêmico de difusão do saber e formador de cidadãos éticos, compromissados com o desenvolvimento do país, indica a necessidade de uma função reguladora por parte dos diferentes conselhos, com uma atuação mais efetiva, para garantir a implantação dos princípios e das bases da educação nacional.

A grande questão que a auto-avaliação enfrenta, no entanto, é a percepção de que se pretende instalar a regulação a partir da implementação da proposta do MEC/Inep/Conaes.

Auto-avaliação distingue-se do controle, da regulação. A função básica da auto-avaliação é a de produzir dados, informações que permitam a tomada de decisões. $\mathrm{O}$ controle deve ser freqüente e tem por objetivo 
regular o cumprimento de decisões já tomadas, com o propósito de manter funções essenciais do sistema de ensino. A auto-avaliação, além de subsidiar a tomada de decisões futuras, exige o desenvolvimento de uma cultura avaliativa, de utilização de dados de diagnóstico, que precisa ser construída.

Para a sua implantação, a auto-avaliação precisa vencer mitos, representações presentes no ideário acadêmico. Mais do que isso, precisa desenvolver um clima de confiança entre a comunidade universitária e os avaliadores, para que essa os veja como avaliadores de sua ação. Desse modo, realizar uma auto-avaliação não pode ser uma arma de gestores universitários que queiram usar seus resultados apenas para constranger, demitir professores e funcionários. A auto-avaliação, como uma prática pedagógica, exige um planejamento estratégico, que busque fins determinados, valores promovidos para o desenvolvimento da instituição, justamente para evitar uma ação de controle interno-punitiva, respaldada por instrumentos legais externos.

O Documento Bases tenta explicitar a relação que existe entre a regulação e a avaliação, considerando que ambas as funções são fundamentais para o desenvolvimento de um ensino superior comprometido com a qualidade, mas não deixa claro que elas supõem metodologia, procedimentos e instrumentos de acompanhamento diferentes. Seria necessário que, ao especificar as estratégias de implantação da auto-avaliação, o Documento Bases estabelecesse os limites e as possibilidades de tal prática pedagógica, identificando suas conseqüências.

\section{PRIORIZAR AS DIMENSÕES: A MISSÃO COMO REFERÊNCIA DA AUTO-AVALIAÇÃO}

As dimensões propostas pelo Documento Bases são amplas e evidenciam uma visão de universidade múltipla, visão esta que deve ser bem coordenada por uma missão que reestrutura todas as atividades e por políticas integradas em um plano de desenvolvimento estratégico institucional - PDI. Segundo essa orientação, Sousa et al. (2005), reagruparam as dez dimensões propostas pelo Documento Bases em três grandes focos, organizados com base na missão da instituição (Figura 1). 


\section{Figura 1 - Organização das Dimensões em Focos de Análise}

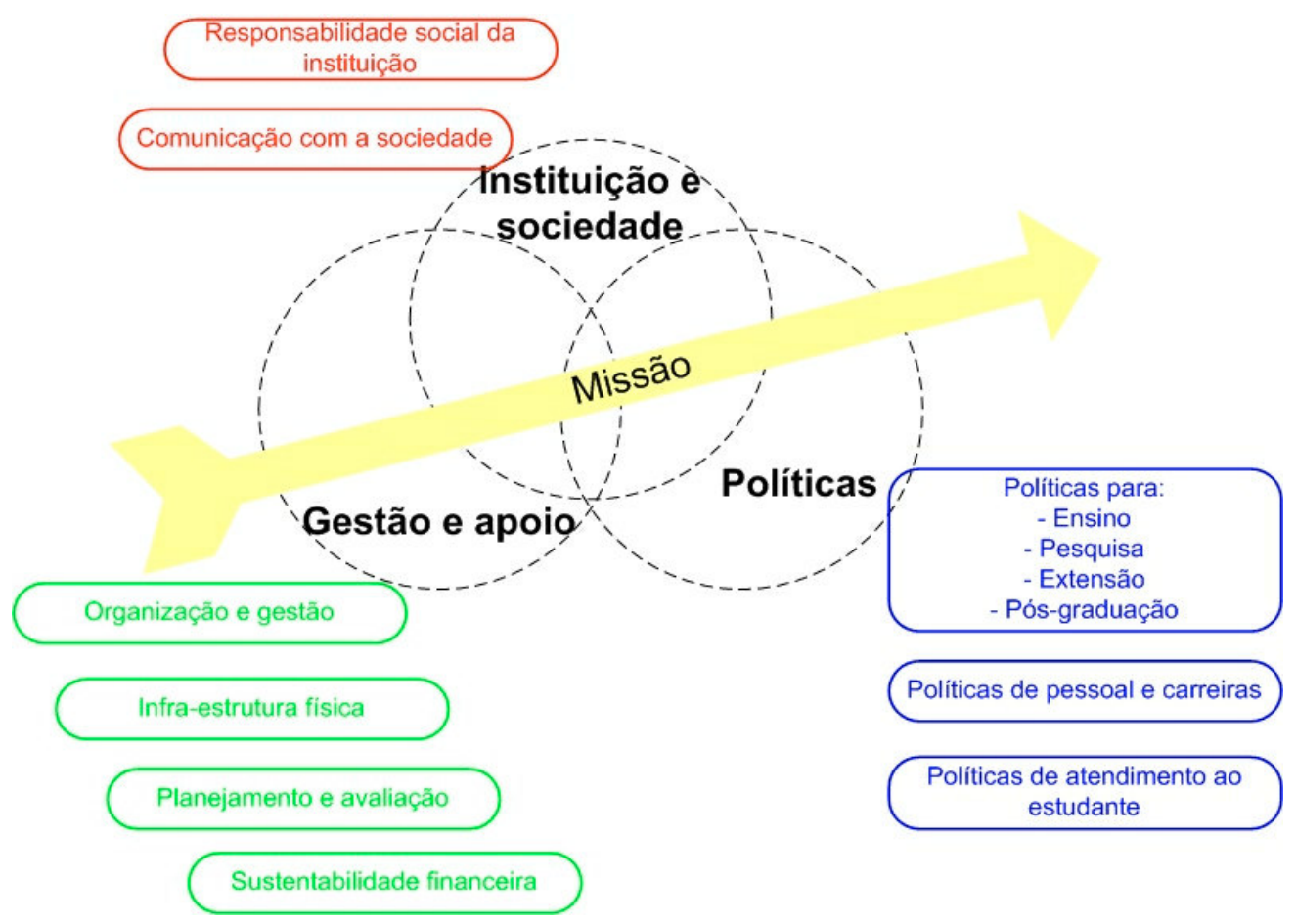

A organização das dimensões em focos de análise tem como referência o documento fundamental da instituição, o PDI, base, portanto, para análise da instituição. Nesse documento são revelados os propósitos, os compromissos sociais e éticos que a instituição assume, que deve ser submetido à aprovação do Conselho Nacional de Educação, e que explicita a missão socioeducacional da instituição. Considerando que muitos professores, funcionários e alunos desconhecem tal documento, ele é, de fato, o elemento norteador das ações para o julgamento das informações coletadas no processo de avaliação. No entanto, em muitas IES, o PDI tem perdido o seu significado original e não reúne mais os compromissos da instituição. Ficou defasado, tornando-se um documento sem vitalidade para agregar e direcionar as ações da universidade. A prática que se desenvolveu na instituição pode ter criado novas exigências sociais, e a experiência vivida pelos atores da comunidade escolar pode estar construindo uma outra visão de universidade que o PDI não mais representa; o que significa dizer que a missão originalmente proposta precisaria ser re-escrita. Neste caso, definir o PDI como referência, como 
critério de avaliação, obrigaria a instituição a restabelecer seus parâmetros de comparação e declarar novamente seus compromissos.

Os atores que convivem na IES produzem, na experiência do cotidiano, um conhecimento da instituição que pode revelar uma realidade diferente daquela descrita nos documentos oficiais. Os sujeitos constroem representações não como um reflexo da realidade externa, mas como uma construção mental de universidade, decorrente de sua atividade simbólica, no contexto do sistema social mais amplo e da experiência vivenciada na instituição (Moscovici, 1978). As representações sociais desses sujeitos sobre a universidade indicam, portanto, seu entendimento sobre o sentido da universidade, sua missão e, ao mesmo tempo, desvelam a cultura construída no cotidiano da instituição, sobre a qual o professor atua e dá sentido à sua prática.

Traduzindo essas considerações em diretrizes metodológicas, podese afirmar que a auto-avaliação terá que tomar esses dois indicativos como critério para sua análise, isto é realizar uma análise comparativa, tendo como referência o ideal, o modelo de universidade proposto no PDI, e, ao mesmo tempo, considerar a instituição que está sendo construída no cotidiano escolar, vivenciado pela comunidade universitária. As duas comparações são importantes porque possibilitam tanto compreender a universidade vivenciada, e que de fato orienta as ações da instituição, quanto analisar os dados, em razão da instituição ideal proposta, indicando a distância entre as ações cotidianas e o modelo idealizado.

\section{CONCLUSÃO}

O Documento Bases precisa ser observado como um documento inacabado, repleto de diretrizes sobre o que é necessário realizar, mas faltam propostas e sugestões de como fazê-lo. Falta a elaboração de um plano de implantação. Na medida em que o MEC/Inep/Conaes reconheça tal característica do documento, completá-lo, passo a passo, ou a cada nova avaliação, será uma possibilidade enriquecedora.

\section{REFERÊNCIAS BIBLIOGRÁFICAS}

BRASIL. Ministério da Educação. Instituto Nacional de Estudos e Pesquisas. Coordenação Nacional de Avaliação do Ensino Superior. Bases para uma nova proposta de avaliação da educação superior. Brasília, 2003. 
BRASIL. Ministério da Educação. Comissão Nacional de Avaliação da Educação Superior - Conaes. Diretrizes para a auto-avaliação das instituições. Brasília: MEC/Inep, 2004.

ACOSTA, Sandra F.; MARCONDES, Anamérica. Relatório de auto-avaliação institucional da PUCSP. São Paulo: CPA/PUCSP. 2006.

MOSCOVICI, S. A Representação social da psicanálise. Rio de Janeiro: Zahar. 1978.

RAJAGOPALAN, K. A Construção de identidades e a política de representação. In: FERREIRA, L.; ORICO, E. (org). Linguagem, identidade e memória social. Rio de Janeiro: DP\&A/Uni-Rio/Faperj, 2002.

SOUSA, Clarilza P. et al. Auto-avaliação institucional da PUC-SP: uma experiência compartilhada. In: ENCONTRO INSTITUCIONAL DAS INSTITUIÇÕES DE ENSINO SUPERIOR ASSOCIADAS DA ABESC E ABRUC. Anais do... Campinas, 2005.

THÉLOT, C. Evaluation du système educatif. Tours: Nathan, 1993.

Recebido em: agosto 2006

Aprovado para publicação em: outubro 2006 